Determinação de Metalotioneínas e Fitoquelatinas utilizando a técnica de HPLC-ICP-MS

\author{
Melendez, L. B.; Kütter, V. T.;* Montes-Bayón, M.; Sella S. M.; Silva-Filho, \\ E. V.
}

Rev. Virtual Quim., 2012, 4 (6), 612-622. Data de publicação na Web: 30 de outubro de 2012

http://www.uff.br/rvq

\title{
Determination of Metallothioneins and Phytochelatins using HPLC-ICPMS
}

Abstract: Metallothioneins and phytochelatins are peptides and proteins associated with metals present in all biological systems. Generally, in the presence of certain metal concentration, they are produced naturally by the body. There are several applications including their use as indicators of environmental pollution and to fight disease. For the determination of metallothioneins and phytochelatins is necessary to use a very detailed chemical analysis procedure that involves the extraction of these complexes, followed by a methodology of separation or purification of compounds extracted and finally by the detection of both the organic compound (the protein) and the metal associated with it. Different strategies should be used whether the subject of the analysis is the apo-form of the biomolecule or the metallic complex. In the second case, special care has to be taken for preserving the metal-biomolecule association along the sample preparation procedure. UV-VIS absorbance, fluorescence or mass spectrometry are often used for detection of the biomolecules. In the case of metallic complexes, high performance liquid chromatography (HPLC - High Resolution Liquid Chromatography) is the most used technique for separation, associated to mass spectrometry with inductively coupled plasma (ICP-MS - Inductively Coupled Plasma Mass Spectrometry), an elemental technique, that allows the detection of metallic ions. Some aspects of this technique and its application are described in this paper.

Keywords: Metallothioneins; phytochelatins; HPLC-ICP-MS.

\section{Resumo}

Metalotioneínas e fitoquelatinas são proteínas e peptídeos associados a metais presentes em todos os sistemas biológicos. Geralmente, na presença de certa concentração de metais, elas são produzidas naturalmente pelo organismo. Existem diversas aplicações destes compostos, incluindo sua utilização como indicadores de poluição ambiental, combate a doenças, etc. Para a identificação de metalotioneínas e fitoquelatinas é necessário utilizar um procedimento bem detalhado de análise química, que envolve a extração destes complexos, seguido da separação ou purificação dos compostos extraídos, e por fim, deteç̧ão. Dependendo dos objetivos a serem alcançados, se a identificação da apo-forma da biomolécula ou do complexo metálico, diferentes estratégias devem ser usadas. No segundo caso, deve-se ter cuidado especial na preservação da ligação metal-biomolécula durante os procedimentos de preparação das amostras. Com relação ao sistema de detecção, a absorbância UV-VIS, fluorescência ou espectrometria de massas são os mais comumente utilizados. No caso de complexos metálicos, a cromatografia líquida de alta eficiência (HPLC) é técnica mais utilizada para a separação, acoplada a espectrometria de massas com plasma indutivamente acoplado (ICP-MS), técnica de detecção de íons metálicos. Este artigo descreve, em linhas gerais, esta técnica e suas aplicações.

Palavras-chave: Metalotioneínas; fitoquelatinas; HPLC-ICP-MS.

\footnotetext{
* Universidade Federal Fluminense, Departamento de Geoquímica, Rua Outeiro de São João Batista s/no, Instituto de Química, 5o andar, CEP 24020-141, Niterói-RJ, Brasil.

$M$ viniciuskutter@yahoo.com.br

DOI: $\underline{10.5935 / 1984-6835.20120047}$
}

Rev. Virtual Quim. |Vol 4| | No. 6| |612-622| 
Volume 4, Número 6

\section{Determinação de Metalotioneínas e Fitoquelatinas utilizando a técnica de HPLC-ICP-MS}

\section{Luana B. Melendez, ${ }^{a}$ Vinicius T. Kütter, ${ }^{b, *}$ Maria Montes-Bayón, ${ }^{c}$ Silvia Maria Sella, ${ }^{a}$ Emmanoel V. Silva-Filhob}

\footnotetext{
a Universidade Federal Fluminense, Departamento de Química Analítica, Rua Outeiro de São João Batista s/no, Instituto de Química, CEP 24020-150, Niterói-RJ, Brasil.

${ }^{\mathrm{b}}$ Universidade Federal Fluminense, Departamento de Geoquímica, Rua Outeiro de São João Batista s/no, Instituto de Química, 5o andar, CEP 24020-150, Niterói-RJ, Brasil.

' Universidade de Oviedo, Departamento e Física e Química Analítica, Oviedo, Espanha.

*viniciuskutter@yahoo.com.br
}

Recebido em 25 de outubro de 2011. Aceito para publicação em 23 de setembro de 2012

\section{Introdução}

2. Análise de MTs e PCs por HPLC-ICP-MS

3. Perspectivas da investigação de MTs e PCs no ambiente marinho

\section{Conclusões}

\section{Introdução}

As metalotioneínas e fitoquelatinas estão presentes em todos os organismos vivos, sendo induzidas as suas sínteses, devido à exposição a metais. Em 1957 foi publicado o primeiro trabalho ainda na forma de resumo relatando metais (Cádmio encontrado em tecido de equino), associado a proteínas. ${ }^{1}$ Já em 1960 foi publicado o primeiro trabalho completo descrevendo proteínas contendo $\mathrm{Cd}$ e, no qual o termo metalotioneínas (MT) foi sugerido para descrever estas proteínas com capacidade para ligar-se a metais. ${ }^{2}$ Desde então muitos foram os avanços nesta área de pesquisa e proteínas associadas a metais vêm sendo encontradas em diversos organismos. A capacidade de peptídeos de ligar-se a metais foi descrita pela primeira vez em 1981. Nesse caso, foi determinado o $\mathrm{Cd}$ associado a peptídeos em amostras de plantas e estes peptídeos foram denominados de fitoquelatinas. $^{3}$

As metalotioneínas (MTs) constituem uma superfamília de metaloproteínas ricas em cisteína e metalopeptídeos com baixo peso molecular. Elas são responsáveis pela regulação intracelular, suprindo a demanda biológica de elementos essenciais como zinco e cobre, e protegendo as células de efeitos deletérios por exposição a elevadas quantidades desses elementos e de metais não essenciais como cádmio, mercúrio, etc. ${ }^{4}$ As MTs se ligam a 7 equivalentes de íons metálicos divalentes, com grande afinidade, através da formação de "clusters" (domínios) metal-sulfidrila, ${ }^{5}$ de acordo como 
representado na figura 1.

As metalotioneínas são encontradas em todos os filos animais, algumas plantas, fungos e cianobactérias. A superfamília de metalotioneínas é subdividida em 15 grupos (Tabela 1).

As fitoquelatinas (PCs) são pequenos peptídeos (2 a $10 \mathrm{kDA}$ ) ricos em cisteína, que, normalmente, contém somente três aminoácidos: acido glutâmico, cisteína e glicina (Figura 2). Contudo, outros aminoácidos podem excepcionalmente estar presentes. A estrutura geral das fitoquelatinas é: ( $\gamma$-glutamil-cisteína) $)_{n}$ glicina ( $n=2-11$ ), assim como as variantes com unidades repetidas de $\mathrm{\gamma}$-glutamil-cisteinila, as quais são formadas em algumas plantas e leveduras (fungos). ${ }^{7}$ As fitoquelatinas são encontradas em algas, plantas, fungos e alguns nematódeos.
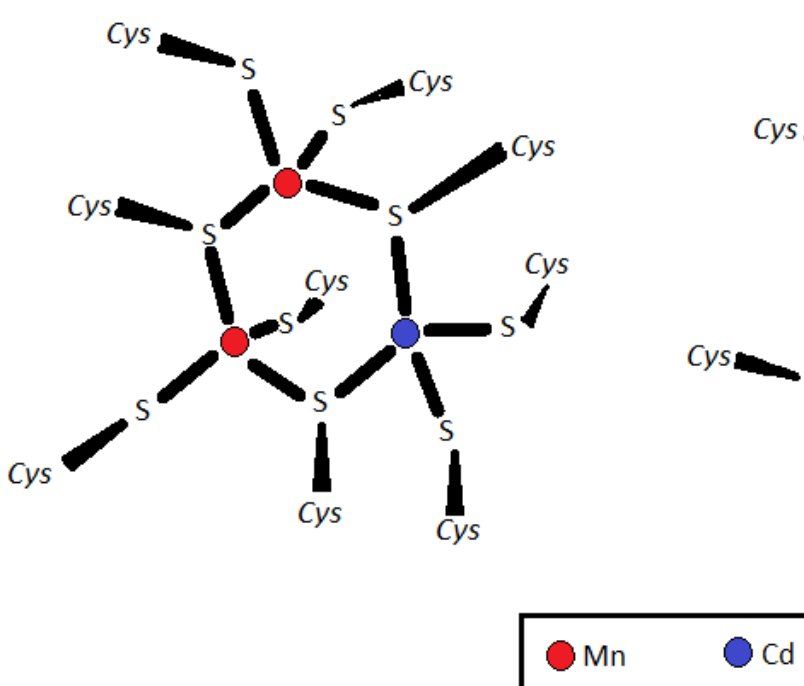

Domínio $\alpha$

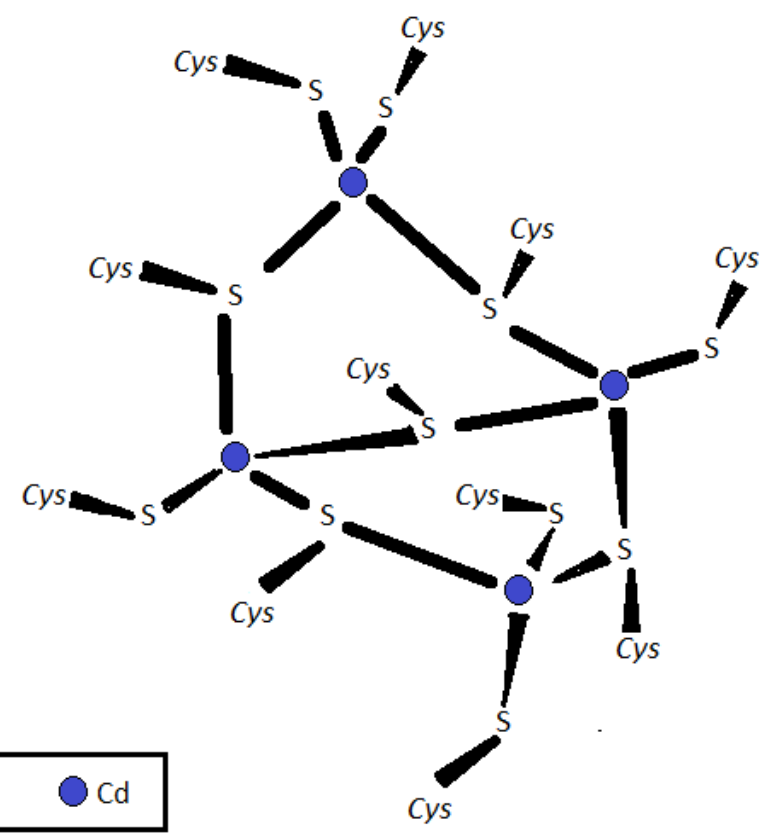

Domínio $\beta$

Figura 1. Sítios para ligação com metais presentes na metalotioneína. Os círculos denotam íons metálicos divalentes (ex. $\left.\mathrm{Zn}^{2+}, \mathrm{Cd}^{2+}, \mathrm{Mn}^{2+}, \mathrm{Cu}^{2+}\right)^{5}$

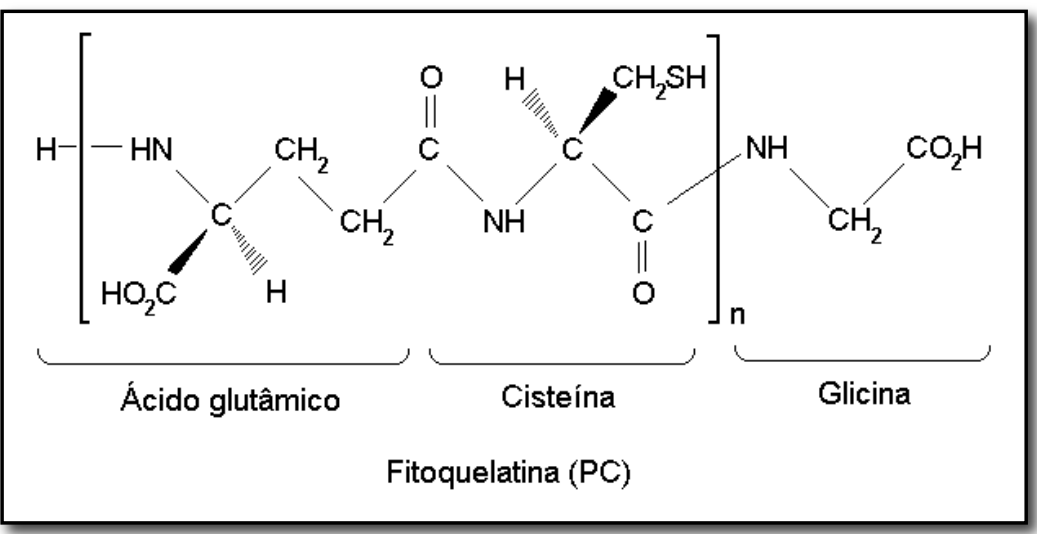

Figura 2. Fórmula estrutural da unidade básica das fitoquelatinas 
Tabela 1. Classificação das metalotioneínas ${ }^{4,6}$

\begin{tabular}{|c|c|c|c|}
\hline Família & \multicolumn{2}{|c|}{ Subdivisões } & Sequência Padrão \\
\hline $\begin{array}{l}\text { Família 1: } \\
\text { vertebrados }\end{array}$ & $\begin{array}{c}\text { m1: mamíferos MT-1 } \\
\text { m2: mamíferos MT-2 } \\
\text { m3: mamíferos MT-3 } \\
\text { m4: mamíferos MT-4 } \\
\text { m: mamíferos MT } \\
\text { a1: aves MT-1 }\end{array}$ & $\begin{array}{c}\text { a2: aves MT-2 } \\
\text { a: aves MT } \\
\text { r: répteis MT } \\
\text { t: teleósteos MT } \\
\text { s: Tubarões MT } \\
\text { b: batráquios (sapos e rãs) } \\
\text { MT }\end{array}$ & $K-x(1,2)-C-C-x-C-C-P-x(2)-C$ \\
\hline $\begin{array}{l}\text { Família 2: } \\
\text { Moluscos }\end{array}$ & $\begin{array}{l}\text { mo1: mexilhão MT-1 } \\
\text { mo2: mexilhão MT-2 }\end{array}$ & $\begin{array}{c}\text { mog: gastrópode MT } \\
\text { mo: outros moluscos MT }\end{array}$ & $\begin{array}{c}C-x-C-x(3)-C-T-G-x(3)-C-x-C-x(3)-C- \\
x-C-K\end{array}$ \\
\hline $\begin{array}{l}\text { Família 3: } \\
\text { crustáceos }\end{array}$ & $\begin{array}{l}\text { c: crustáceos MT } \\
\text { c1: crustáceos MT-1 }\end{array}$ & c2: crustáceos MT-2 & $P-[G D]-P-C-C-x(3,4)-C-x-C$ \\
\hline $\begin{array}{c}\text { Família 4: } \\
\text { Equinodermos }\end{array}$ & $\begin{array}{l}\text { e1: equinoderma MT } \\
\text { tipo } 1\end{array}$ & e2: equinoderma MT tipo 2 & $\begin{array}{c}\text { P-D-x-K-C-V-C-C-x(5)-C-x-C-x(4)-C- } \\
C-x(4)-C-C-x(4,6)-C-C\end{array}$ \\
\hline $\begin{array}{l}\text { Família 5: } \\
\text { Díptera }\end{array}$ & d1: diptera MT tipo 1 & d2: diptera MT type 2 & $\begin{array}{c}C-G-x(2)-C-x-C-x(2)-Q-x(5)-C-x-C- \\
x(2)-D-C-x-C\end{array}$ \\
\hline $\begin{array}{l}\text { Família 6: } \\
\text { Nematoda }\end{array}$ & $\begin{array}{l}\text { n1: nematoda MT } \\
\text { tipo } 1\end{array}$ & n2: nematoda MT tipo 2 & $K-C-C-x(3)-C-C$ \\
\hline $\begin{array}{l}\text { Família 7: } \\
\text { Ciliados }\end{array}$ & ci: ciliata MT & & - \\
\hline $\begin{array}{l}\text { Família 8: } \\
\text { Fungi I }\end{array}$ & f1: fungi-I & & $\begin{array}{c}\text { C-G-C-S-x(4)-C-x-C-x(3,4)-C-x-C-S- } \\
x-C\end{array}$ \\
\hline $\begin{array}{l}\text { Família 9: } \\
\text { Fungi II }\end{array}$ & f2: fungi-II & & - \\
\hline $\begin{array}{l}\text { Família 10: } \\
\text { Fungi III }\end{array}$ & f3 & & - \\
\hline $\begin{array}{l}\text { Família 11: } \\
\text { Fungi IV }\end{array}$ & f4: fungi-IV & & $C-X-K-C-x-C-x(2)-C-K-C$ \\
\hline $\begin{array}{l}\text { Família 12: } \\
\text { Fungi V }\end{array}$ & f5: fungi-V & & - \\
\hline $\begin{array}{l}\text { Família 13: } \\
\text { Fungi VI }\end{array}$ & f6: fungi-VI & & - \\
\hline $\begin{array}{l}\text { Família 14: } \\
\text { Procariota }\end{array}$ & pr: procariota & & K-C-A-C-x(2)-C-L-C \\
\hline $\begin{array}{l}\text { Família 15: } \\
\text { Plantas }\end{array}$ & $\begin{array}{l}\text { p1: planta MT tipo } 1 \\
\text { p2: planta MT tipo } 2 \\
\text { p3: planta MT tipo } 3\end{array}$ & $\begin{array}{l}\text { p21: planta MT tipo } 2 \times 1 \\
\text { pec: planta EC MT-like } \\
\text { proteína }\end{array}$ & $\begin{array}{c}{[\mathrm{YFH}]-\mathrm{x}(5,25)-\mathrm{C}-[\mathrm{SKD}]-\mathrm{C}-[\mathrm{GA}]-} \\
{[\mathrm{SDPAT}]-\mathrm{x}(0,1)-\mathrm{C}-\mathrm{x}-[\mathrm{CYF}]}\end{array}$ \\
\hline $\begin{array}{l}\text { Família 99: } \\
\text { Fitoquelatinas } \\
\text { e outros não } \\
\text { proteináceos } \\
\text { MT-como } \\
\text { polipeptídeos }\end{array}$ & Não definido & & - \\
\hline
\end{tabular}


A produção de fitoquelatinas e metalotioneínas ocorre com a finalidade de proteger o organismo da ação dos metais tóxicos não essenciais, como $\mathrm{Cd}$ e $\mathrm{As}$, ou metais essenciais em excesso, que se tornam tóxicos, como Zn e Cu.

O estudo das metalotioneínas e das fitoquelatinas é de grande importância, tanto no ponto de vista ambiental, para avaliação da qualidade de ambientes terrestres e aquáticos, tendo em vista que a acumulação de metais pela biota pode ser usada como indicador de poluição ambiental, como no ponto de vista tecnológico, já que algumas plantas e algas são organismos resistentes que hiper-acumulam metais e podem ser usadas com a finalidade de remediação de áreas contaminadas por metais, como solos e águas. Além disso, na área médica, a produção de metalotioneínas pelo organismo é uma ferramenta para o desenvolvimento de tratamento de doenças usando metais como componentes de fármacos.

Uma das vantagens do uso de metalotioneínas e das fitoquelatinas como indicadores é o fato de a produção destas ser um indicador precoce de exposição a metais, respondendo bem antes que seja possível mensurar um efeito fisiológico no organismo como alteração na taxa de crescimento ou diminuição da capacidade reprodutiva $^{8}$ (Figura 3).

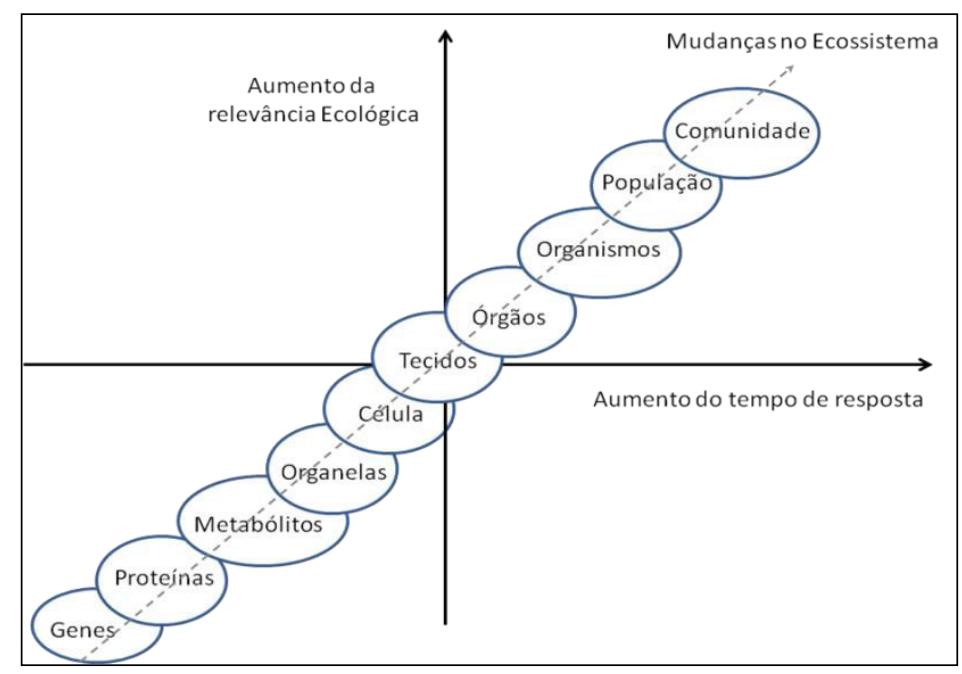

Figura 3. Relação entre relevância ecológica, escala de tempo de resposta e o estudo em diferentes níveis de organização biológica após exposição a um fator estressante (Modificado da referência 9). As metalotioneínas encontram-se no nível das proteínas

$\mathrm{Na}$ área ambiental, uma das grandes aplicações da determinação de fitoquelatinas é a seleção de espécies capazes de hiperacumular metais para utilização no processo de fitorremediação, que possibilita a descontaminação de ambientes pela sorção de metais pelas plantas. Este processo pode ser caracterizado como "limpo", com a vantagem adicional de alterar muito pouco as propriedades biológicas e a estrutura física dos solos. As estratégias de fitorremediação podem oferecer procedimentos adequados para descontaminação de solos, água e ar tanto para elementos-traço quanto para substâncias orgânicas.

$\mathrm{Na}$ área médica, além da detoxificação de metais, as metalotioneínas estão relacionadas ao combate aos radicais livres. Os radicais livres são moléculas que tem um número ímpar de elétrons em sua última camada, o que os torna bastante reativos. Esses radicais reagem com proteínas, gorduras ou mesmo o DNA para abstração de um elétron. Cada molécula que perde um elétron precisa "furtar" o elétron de alguma outra molécula. Esse processo evolui em progressão e é chamado de cascata oxidativa. 
Já a carga total de radicais livres é chamada de estresse oxidativo. As substâncias que fornecem o elétron que está faltando, devolvendo a situação à normalidade são os antioxidantes. $O$ estresse oxidativo é regulado por uma combinação de fatores hereditários, do ambiente e do estilo de vida. Os radicais livres causam lesões tanto nas células como nos genes. Muitos consideram que o acúmulo dessas lesões ao longo da vida favorece a manifestação de doenças relacionadas ao envelhecimento (Figura 4).

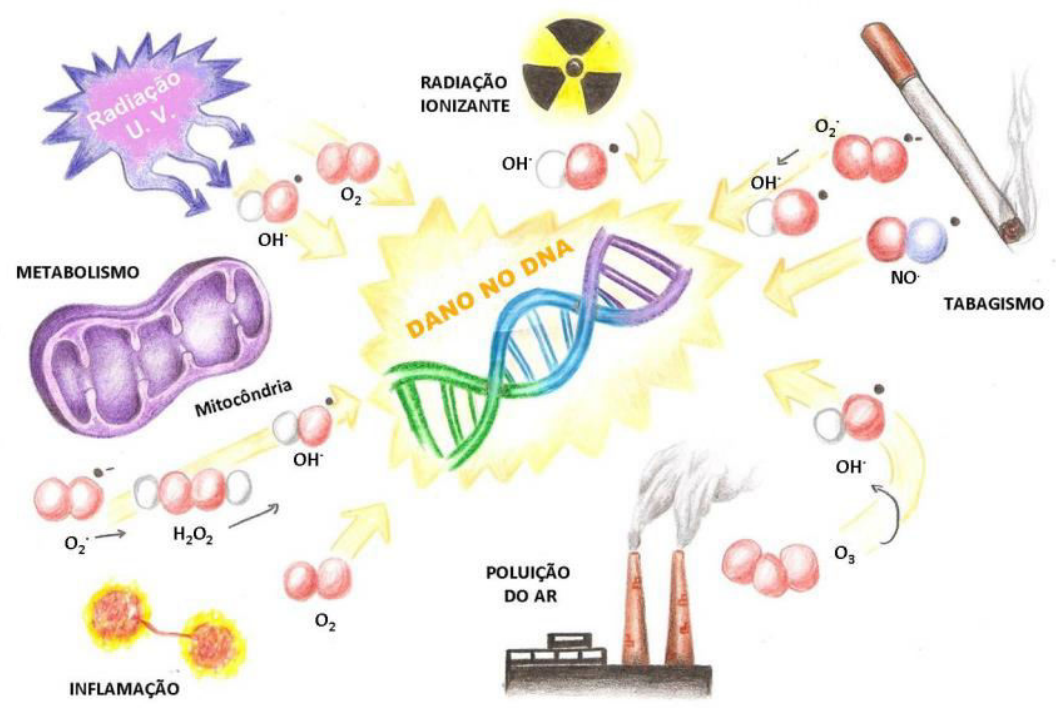

Figura 4. Fatores que favorecem a formação de radicais livres

Essas diversas aplicações das MTs e PCs requerem estudos aprofundados a respeito da produção dessas substâncias pelos diversos organismos vivos.

Atualmente na química analítica, inúmeras metodologias são empregadas na investigação de MTs e PCs. Dentre as técnicas mais usadas estão a eletroforese, a cromatografia líquida de alta eficiência acoplada a espectrômetro de massas com plasma indutivamente acoplado (HPLC-ICPMS) e a espectrometria de massas com ionização por eletrospray (ESI-MS). Nos últimos anos, a técnica de cromatografia líquida de alta eficiência acoplada a espectrômetro de massas com plasma indutivamente acoplado (HPLC-ICP-MS) vem se popularizando por possuir inúmeras vantagens. A técnica de HPLC oferece melhor separação de proteínas e peptídeos e pode ser acoplada facilmente com o ICP, com grandes vantagens em relação à eletroforese.
Já o ICP-MS oferece altíssima sensibilidade na determinação de metais, possibilitando detectar quantidades muito baixas, na faixa de ppb ( $\left.\mu \mathrm{g} \cdot \mathrm{kg}^{-1}\right)$.

O uso de HPLC com detector UV, para visualizar a separação das proteínas ou peptídeos, é uma valiosa ferramenta para estudo de MTs e PCs quando acoplada a um equipamento de ICP-MS, permitindo detectar os metais associados às proteínas e peptídeos.

\section{Análise de MTs e PCs por HPLC- ICP-MS}

O primeiro passo na investigação de metais associados à MTs e PCs é a determinação da concentração total do metal por ICP-MS, após digestão ácida da amostra. 
A segunda etapa é a extração de proteínas e polipeptídeos contendo metais. Nesse processo, inúmeras são as metodologias empregadas, sendo as mais usualmente utilizadas a extração com solução tampão (Tris- $\mathrm{HCl}$ em diferentes $\mathrm{pHs}$ ), também podendo ser utilizada a extração térmica. Após a extração é iniciado o estudo de proteínas presentes no extrato, usando cromatografia (Figura 5). Geralmente, se utiliza cromatografia de exclusão por tamanho (SEC) para uma separação inicial. A cromatografia de exclusão por tamanho é capaz de separar as proteínas e peptídeos contidos no extrato por faixa de tamanho que são detectados por UV-VIS. Os comprimentos de onda mais utilizados para as fitoquelatinas são 254 ou $280 \mathrm{~nm}$, enquanto que para metalotioneínas são mais comumente empregados 220 e $254 \mathrm{~nm}$. Em alguns casos, comprimentos de onda na faixa do visível podem ser utilizados, como por exemplo, para metalotioneína associada ao vanádio em uma espécie de Ascídia, onde se usa $756 \mathrm{~nm} .^{10}$

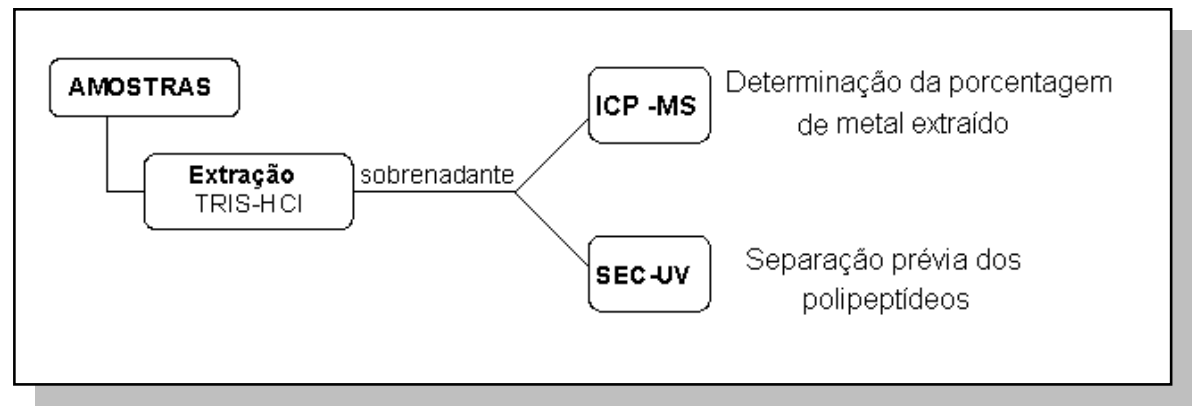

Figura 5. Fluxograma de procedimento usado para extração e investigações iniciais

Nesta etapa, a SEC-UV é acoplada ao ICPMS para verificação da correspondência entre os picos de proteína obtidos no UV e os picos de íons metálicos (Figura 6).

As frações de polipeptídeos e proteínas separadas por SEC são recolhidas para uma segunda fase de separação, utilizando uma coluna que separe melhor os polipeptídeos ou proteínas, podendo ser uma coluna de troca iônica, fase normal ou fase reversa. A escolha do tipo de coluna adequado para a segunda etapa da separação irá depender da estabilidade do complexo metal-biomolécula a ser estudado. ${ }^{11}$

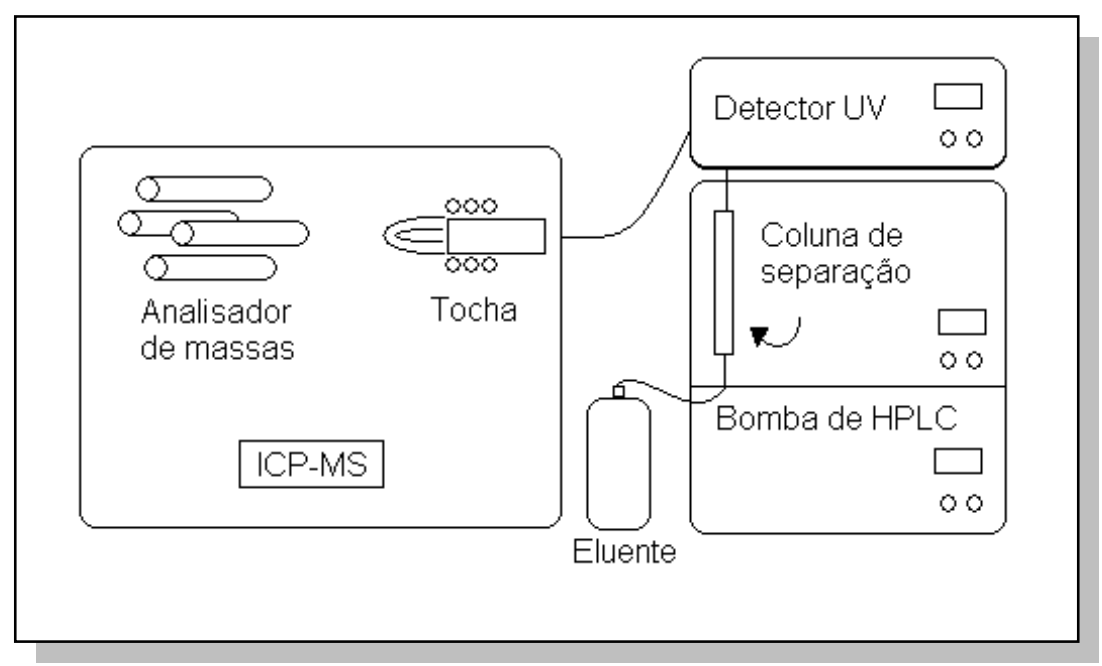

Figura 6. Esquema acoplado HPLC-ICPMS 
Uma aplicação da técnica foi realizada em um estudo de espécies de plantas hiperacumuladoras de arsênio $^{12}$. Neste estudo, uma coluna Superdex Peptide foi utilizada para separação dos peptídeos e foi possível observar a associação de fitoquelatinas a arsênio, como mostrado na Figura 7, no cromatograma obtido para a espécie de planta Pityrogramma calomelanos, considerada hiperacumuladora de As.
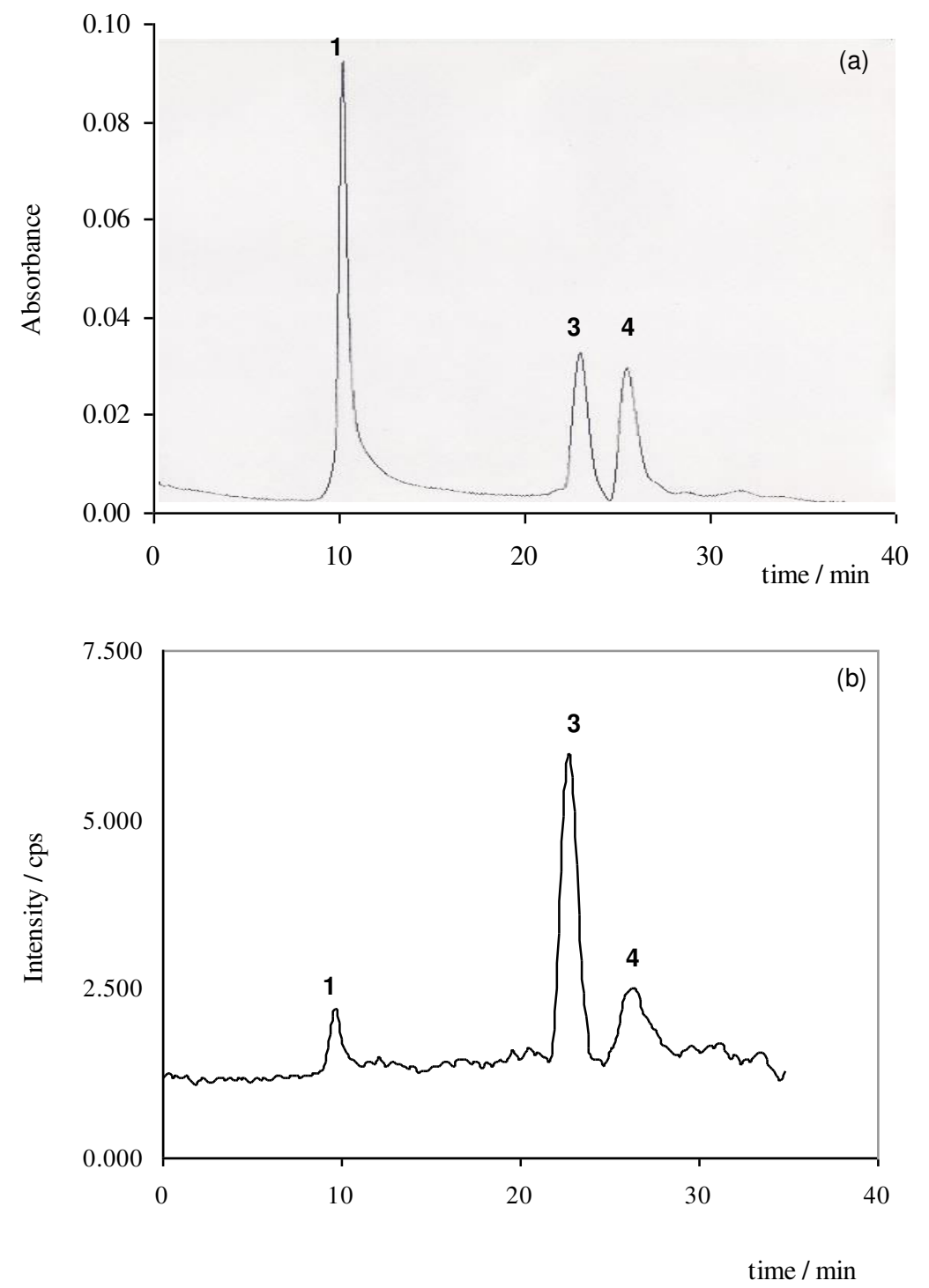

Figura 7. Cromatograma de fitoquelatinas associadas a arsênio em $P$. calomelanos. (a): Peptídeos monitorados por detector UV. (b): arsênio monitorado por ICP-MS ${ }^{12}$ 
Uma dificuldade que vem sendo encontrada nesta linha de pesquisa é a falta de materiais de referências certificados para fitoquelatinas e metalotioneínas. Por esta razão, técnicas complementares de identificação de moléculas orgânicas são utilizadas para garantir a identificação das espécies separadas por cromatografia.

Apesar da farta disponibilidade de dados moleculares sobre a biossíntese de PCs em plantas submetidas a estresse por $\mathrm{Cd}$ e $\mathrm{Cu}$, pouco se sabe sobre as formas moleculares dos complexos formados entre metais e peptídeos nas plantas hiperacumuladoras. Os primeiros espectros de massas eletrospray (ESI-MS) de complexos metal-PCs foram obtidos em 1997. No entanto, somente em 1999 foi publicado o primeiro espectro de massas. $^{13}$ A dificuldade com relação à estabilidade do complexo metal-biomolécula, frequentemente muito lábil, é um ponto crítico da técnica.

\section{Perspectivas da investigação de MTs e PCs no ambiente marinho}

Com o avanço da industrialização no último século, as emissões de substâncias tóxicas vêm tendo uma elevação tremenda e significativa, sendo uma grande preocupação nos dias de hoje o controle da emissão de poluentes e a remediação de áreas contaminadas.

Inúmeras são as atividades humanas que afetam a qualidade ambiental de áreas costeiras $^{13}$ (lixo, descarga de efluentes, disposição de sedimentos dragados, exploração de petróleo, etc). Além disso, mais de 3 bilhões de pessoas vivem a até 200 $\mathrm{Km}$ da costa, ou seja metade da população mundial. $^{14}$

Dentre a imensa variedade de substâncias químicas lançadas pelo homem no ambiente, destacam-se os metais.

Windom $^{15}$ descreve as 7 maiores categorias de contaminantes (lixo, efluente de esgoto, petróleo, metais, compostos orgânicos sintéticos, mobilização antropogênica de sedimento, e nutrientes) de origem continental que tem perseverança no ambiente e/ou geram efeitos adversos ao ambiente marinho. Nesse trabalho, Windom relata que entre as sete maiores categorias de contaminantes, os metais são o principal grupo, uma vez que suas emissões são pouco tratadas em escala global.

Nesse contexto, a utilização de ferramentas que permitam identificar precocemente a exposição da biota marinha a metais é de suma importância para o monitoramento e gerenciamento de áreas costeiras. Tendo em vista, o fato da indução da síntese de metalotioneínas em muitas espécies marinhas devido a contaminação por metais ( $\mathrm{Ag}, \mathrm{Cd}, \mathrm{Cu}, \mathrm{Hg}$ ), tem liderado a proposta de uso desta superfamília como um potencial biomarcador para exposição aos metais em organismos biomonitores aquáticos, ${ }^{16,17}$ sendo que fatores naturais e fisiológicos tem que ser considerados. ${ }^{18}$

O monitoramento das concentrações de MTs e PCs em organismos marinhos pode ser uma ferramenta eficaz em apontar precocemente os dados antrópicos ao sistema marinho, e possibilitar a tomada de decisão de gerenciamento mais adequada da área contaminada ou espécie afetada, antes que ocorra um dano maior a todo o ecossistema.

São poucos os estudos de MTs e PCs em organismos marinhos em comparação a grande diversidade de espécies existentes. Em recente trabalho publicado por Devez ${ }^{19}$ et al., no qual estes autores revisam os trabalhos de PCs em algas, foram encontrados apenas 34 trabalhos relatando a produção de PCs em algas marinhas e estuarinas, sendo que grande parte destes estudos tratam de ensaios de laboratório. $\mathrm{Na}$ literatura são mencionados apenas 17 trabalhos descrevendo a ocorrência de PCs em comunidades naturais, em estuários e áreas costeiras do Oceano Atlântico Norte, Oceano Pacífico Equatorial, Oceano Pacifico Subártico e para o Mar Egeu no Mediterrâneo. 
Esta deficiência de dados de MT e PCs em organismos marinhos em campo dificultam o estabelecimento de valores naturais "background" de MTs e PCs, e a utilização desta ferramenta em rotina no biomonitoramento de áreas costeiras. Entretanto, alguns autores mostraram a aplicabilidade da investigação da concentração de PCs e MTs para biomonitoramento, como exemplo no fitoplâncton $^{20}$ e em mexilhão, ${ }^{21}$ em áreas portuárias e costeiras.

\section{Conclusões}

0 estudo de fitoquelatinas e metalotioneínas em organismos vivos é de extrema importância em diversas linhas de pesquisas, seja em estudos de biomonitoramento, de fitorremediação ou na área da medicina. Por esta razão, técnicas analíticas estão sendo desenvolvidas e aplicadas para o estudo dessas espécies. A técnica analítica de HPLC-UV-ICP-MS é a que mais vêm sendo empregada em pesquisas nesta área, por ser uma ferramenta que possibilita o estudo do metal e da biomolécula. No entanto, técnicas ainda mais avançadas já estão sendo aplicadas.

\section{Agradecimentos}

A CAPES (PDEE- BEX- 455209-1 Vinicius T. Kutter), a FAPERJ (Fundação de Amparo à Pesquisa do Estado do Rio de Janeiro, PROC. 101.814/2009; E-26/102.814/2008) ) e ao Instituto Nacional de Ciência e Tecnologia (INCT-TMCOcean 573-601/2008-9).

\section{Referências Bibliográficas}

\footnotetext{
${ }^{1}$ Margoshes, M.; Vallee, B. L. J. Am. Chem. Soc. 1957, 79, 4813. [CrossRef]

2 Kägi, J. H. R.; Vallee, B. L. J. Biol. Chem. 1960, 235, 3460. [PubMed] [Link]
}

${ }^{3}$ Murasugi, A.; Wada, C.; Hayashy, Y. J. J. Biochem. 1981, 90, 1561. [PubMed]

${ }^{4}$ Sitio da Expansy, 2010. Disponível em: <http://www.uniprot.org/docs/metallo.txt>. Acesso em: 25 setembro 2012.

${ }^{5}$ Chang, C. C.; Lee, S. F.; Sun, K. W; Ho, C. C.; Chen, Y. T.; Chang, C. H.; Kan, L. S. Biochem. Biophys. Res. Commun. 2006, 340, 1134. [CrossRef] [PubMed]

${ }^{6}$ Binz, P. A.; Kägi, J. H. R. Em: Metallothionein IV, Klaassen, C. D., ed Birkhauser Verlag:Basel, 1999, Cap 1.

7 Inouhe, M. Braz. J. Plant Physiol. 2005, 17, 65. [CrossRef]

${ }^{8}$ Monserrat, J. M.; Martínez, P. E.; Geracitano, L. A.; Amado L. L.; Martins, C. M. G.; Pinho, G. L. L.; Chaves, I. S.; FerreiraCravo, M.; Ventura-Lima J.; Bianchini, A. Comp. Biochem. Physiol., Part C: Toxicol. Pharmacol. 2007, 146, 221. [CrossRef] [PubMed]

${ }^{9}$ Lemos, M. F. L.; Soares, A. M. V. M.; Correia, A. C., Esteves, A. C. Proteomics 2010, 10, 873. [CrossRef] [PubMed]

${ }^{10}$ Michibata, H.; Hirose, H.; Sugiyama, K.; Ookubo, Y.; Kanamori, K. Biol. Bull. 1990, 179, 140. [CrossRef]

${ }^{11}$ Bettmer, J.; Bayón, M. M.; Encinar, J. R.; Sánchez, M. L. F.; de la Campa, M. R. F.; Medel, A. S. J. Proteomics 2009, 72, 989. [CrossRef] [PubMed]

12 Melendez, L. B.; Silva-Filho, E. V.; Miekeley, N.; Vieira, F. A.; Sella, S. M. J. Braz. Chem.

Soc., 2011, 22, 1961. [CrossRef]

${ }^{13}$ Vacchina, V.; Chassaigne, H.; Lobinski, R.; Oven, M.; Zenk, M. H. Analyst 1999, 124, 1425. [CrossRef]

14 Pinet, P. R.; Invitation to Oceanography. 3a. ed., Jones and Bartlett Publishers: Burlington, 2003.

${ }^{15}$ Windom, H. L. Mar. Pollut. Bull. 1992, 25, 32. [CrossRef] 
${ }^{16}$ Cajaraville, M. P.; Bebianno, M. J.; Blasco, J.; Porte, C.; Sarasquete, C.; Viarengo, A. Sci. Total Environ. 2000, 247, 295. [CrossRef]

${ }^{17}$ Amiard, J. C.; Amiard-Triquet, C.; Barka, S.; Pellerin, J.; Rainbow, P. S. Aquat. Toxicol. 2006, 76, 160. [CrossRef] [PubMed]

${ }^{18}$ Legras, S.; Mouneyrac, C.; Amiard, J. C.; Amiard-Triquet, C.; Rainbow, P. S. J. Exp. Mar. Biol. Ecol. 2000, 246, 259. [CrossRef]

${ }^{19}$ Devez, A.; Achterberg, E.; Gledhill, M. Em Metal Ions in Life Sciences; Sigel, A.; Sigel, H.;
Sigel, R. K. O., eds.; Royal Society of Chemistry Publishing:Cambridge, 2009, cap. 15.

${ }^{20}$ Ahner, B. A.; Morel, F. M. M.; Moffett, J. W. Limnol. Oceanogr. 1997, 42, 601. [CrossRef]

${ }^{21}$ Lionetto, M. G.; Giordano, M. E.; Caricato, R.; Pascariello, M. F.; Marinosci, L.; Schettino, T. Aquat. Conserv. Mar. Freshwat. Ecosyst. 2001, 11, 305. [CrossRef] 